\title{
Trends in Years Spent as Mothers of Young Children: The Role of Completed Fertility, Birth Spacing, and Multiple Partner Fertility
}

\author{
Christine R. Schwartz, Catherine Doren, and Anita $\mathbf{L i}^{1}$
}

\begin{abstract}
The number of years women spend as mothers of young children likely has implications for women's lifetime wages, earnings, and time use. Much prior research has pointed to widening education differences in a wide array of family patterns, but none has examined trends in the number of years women spend as mothers of young children. We use retrospective fertility data from the 2014 Survey of Income and Program Participation to show how changes in women's completed fertility and birth spacing produce trends in years women spend as mothers of children under age six from 1967 to 2017. Despite remarkably parallel declines in completed fertility, growing educational differences in birth spacing produced educational divergence in years spent as mothers of young children. Particularly striking is the finding that increases in birth spacing reversed declines in years spent as mothers for women with less than a high school degree such that they spent more years with young children in the 2010s than in the late 1960s. The increasing prevalence of multiple partner fertility explains some but not all of these trends.
\end{abstract}

\section{Introduction}

Patterns of family formation, dissolution, and childbearing have diverged sharply by women's education over the past several decades (Isen and Stevenson 2011; Matthews and Hamilton

C.R. Schwartz (corresponding author)

Department of Sociology, University of Wisconsin-Madison, Madison, WI, USA

e-mail: cschwart@ssc.wisc.edu

C. Doren

Office of Population Research, Princeton University, Princeton, NJ, USA

e-mail: cdoren@princeton.edu

A. $\mathrm{Li}$

Department of Sociology, University of Wisconsin-Madison, Madison, WI, USA

e-mail: hli666@wisc.edu 
2009; McLanahan 2004). Women with less education are less likely to marry, more likely to divorce, more likely to have children earlier in their lives, and more likely to bear children outside marriage and with multiple partners (Smock and Schwartz 2020). These changes have been interpreted within a framework of "diverging destinies," which points to growing inequality in numerous family and demographic patterns associated with children's wellbeing (McLanahan 2004), patterns that have also been documented in other countries (e.g., Härkönen 2017; Kalmijn 2013; McLanahan 2004; Raymo et al. 2015).

An important but thus far unexplored aspect of trends in family life is the number of years women spend as mothers of young children. Mothers continue to experience wage penalties (Avellar and Smock 2003; Pal and Waldfogel 2016), and having young children is associated with lower rates of labor force participation (Cotter, England, and Hermsen 2007). Thus, an increase in the number of years less educated women spend with young children relative to their more highly educated counterparts may have contributed to growing wage and earnings inequality among women since the 1960s (Autor 2014). The number of years women spend as mothers of young children may also have major implications for time use patterns given that women with young children perform less labor market work and spend significantly more time on child care activities (Cotter et al. 2007; Kalil, Ryan, and Corey 2012; Meier, Musick, Fischer, and Flood 2018). Thus, the number of years women spend as mothers of young children may be associated with prolonged motherhood wage penalties and labor market participation reductions as well as increased child care responsibilities.

This chapter examines how changes in the number of children ever born, birth timing, and multiple partner fertility (MPF) have impacted the number of years women spend as biological mothers of young children. Holding constant other changes, declines in fertility will reduce the number of years women spend as biological mothers of young children. However, changes in birth spacing may counterbalance the effects of fertility decline. For example, a woman who bears twins and no subsequent children will have children under the age of six for just 6 years. By contrast, a woman who has two children 6 years apart will have children under the age of six for 12 years. We investigate the extent to which changes in the number of years women with different levels of education spend as biological mothers of young children are a function of declines in completed fertility versus birth spacing and investigate the role of MPF in these processes. Past research has described trends in completed fertility by education (Isen and Stevenson 2011; Yang and Morgan 2003), but there is far less work on birth spacing and years spent as mothers in the United States (King 1999; Wineberg and McCarthy 1989).

We expect that changes in birth spacing will be particularly important for less educated women. Prior research has shown that when women enter a new union, they are more likely to have an additional child (Guzzo 2014; Thomson, Winkler-Dworak, Spielauer, and Prskawetz 2012). Estimates of the proportion of disadvantaged women who have children with different partners are high. For example, Fomby and Bosick (2013) find that nearly $60 \%$ of unmarried mothers had given birth to a child with a different partner within nine years. If changing partners is associated with wider birth intervals as well as additional births, the rise in MPF will have increased the number of years spent with young children to a greater extent for less educated women than their more highly educated counterparts.

What about social motherhood? Family structure has changed considerably in the United States and social motherhood (e.g., step, adoptive, and foster parenthood) is common. At the same time, $90 \%$ of mothers live with all of their biological children under 18 years of age (Monte 2017). In addition, the focus of this chapter is years spent as mothers of children under age six 
and stepchildren and other non-biological children often join families at older ages. In 2010,97\% of children under age six in households were the householder's biological children whereas $1.7 \%$ were adopted and 1.4\% were stepchildren (Kreider and Lofquist 2014). Thus, although nonbiological children may add a non-trivial amount of time to the years women spend as mothers of children of all ages and this is also likely to vary significantly by education, because our focus is on young children, the exclusion of non-biological children is unlikely to significantly affect our estimates. We test the sensitivity of our analyses where possible using data on both biological and non-biological children and find broadly consistent trends to those using biological children alone.

\section{Background}

Past research on trends in completed fertility and birth spacing offers clues about the likely direction of change in time spent as mothers of young children in the United States. Although educational differences have grown on most markers of family patterns in the United States, completed fertility is a notable exception. Since the 1960s, differences in the total number of children born to women by education have been remarkably parallel (Isen and Stevenson 2011; Yang and Morgan 2003). Highly educated women have long had fewer children than women with less education. For example, in 2012-2014, college graduates aged 40 to 44 had 2.2 children on average in their lifetimes compared with 2.9 children for women without a high school diploma (Livingston, Parker, and Rohal 2015). Overall, total fertility has declined. Most of the decline was concentrated at the end of the baby boom from 1960 to the mid-1970s and there has been relatively little change since then (Smock and Schwartz 2020). Despite these trends, education differences in completed fertility have been relatively stable. If anything, there may be movement toward convergence as the fertility of very highly educated women (master's or professional degree or more) has increased in recent cohorts (Hazan and Zoabi 2015; Livingston et al. 2015; Shang and Weinberg 2013). These findings suggest that trends in completed fertility will not be the source of divergence in years spent as mothers of young children.

There is little research on trends in birth spacing in the United States, but data from the 1980s suggests that birth spacing was increasing at that time (Wineberg and McCarthy 1989). Information on trends in birth spacing by education does not exist to our knowledge, but given concurrent changes in family formation patterns and the rise of MPF, we expect average birth spacing by education to have diverged. Prior research has shown that when women enter a new union, they are more likely to have an additional child (Holland and Thomson 2011; Thomson, Lappegård, Carlson, Evans, and Gray 2014; Thomson et al. 2012). These new births may be at wider intervals given that women who change partners may go through a period of lower fertility when they are out of unions or in unstable unions, a pattern supported by empirical research (Li 2006). Because the prevalence of MPF has grown substantially, especially among less educated women (Amorim and Tach 2019), trends in birth spacing may be contributing to growing educational inequality in years spent as mothers of young children in the United States.

\section{Data \& Methods}


Our primary analysis uses retrospective fertility histories from Waves 1-4 of the 2014 Survey of Income and Program Participation (SIPP). The 2014 SIPP is a longitudinal panel in which each household was interviewed once a year across four years. Data from all four waves (interviews from 2014 to 2017) are used in our analyses. Because we are interested in completed fertility, our sample is comprised of women aged 40 and over - an age past which few women continue having children. We use all four available waves of the 2014 SIPP to maximize our sample size. Because the survey is longitudinal, however, we select only the first observation in which women are age 40 or over. Our final sample is comprised of 21,226 women aged 40 and above. With these data, we classify women according to the year in which they turned 40 and are thus able to examine trends in fertility and birth spacing from 1967 to 2017 . Although it is possible that differential female mortality may affect our results given estimates for earlier years rely on older cohorts of women, we believe that this is unlikely to be a concern given that our results are very similar to published fertility trends and patterns using cross-sectional (rather than retrospective) data.

We use a four-category representation of women's education based on the highest level of school or degree respondents had completed at the time of the survey (less than high school, high school or GED, some college or associate's degree, bachelor's or higher). Over this period, women's education increased substantially. Trends in the distribution of women's education from the SIPP arranged by the year in which women turned 40 (see Appendix Table 1) closely mirror those using cross-sectional Current Population Survey data (U.S. Census Bureau 2019a). Year groupings are by decade (1967-69, 1970-79, 1980-89, 1990-99, 2000-09, 2010-17).

The 2014 SIPP was the first nationally representative survey to include a direct question about MPF, which is measured by the question "Do you have children with more than one partner?" and was asked of respondents over age 15 with at least one biological child. Other surveys infer MPF from answers to questions such as the alignment of partnership dates and children's birth dates. An assessment of different approaches to measuring the prevalence of MPF suggests that the SIPP's direct question may underestimate the prevalence of MPF, perhaps due to social desirability bias. There is also evidence that this may especially be the case for more disadvantaged populations (Stykes and Guzzo 2019). It is important to keep this in mind and we return to the implications of this potential underestimate in the discussion of our results.

We estimate the number of years that women spend as biological mothers of children under age six using the following formula separately for each education group $(j)$ and year group $(t)$ :

$$
\left(\left(\left[c f_{j t}-1\right] * s_{j t}\right)+6\right) * p_{j t}
$$

There are three components to this equation: (1) average completed fertility among women with children $\left(c f_{j t}\right.$, defined as the number of children ever born among women age 40 and over in education group $j$ and year $t$ who reported one or more birth), (2) average birth spacing $\left(s_{j t}\right.$, defined as the average difference between women's children's birth years for women with more than one child in education group $j$ and year $t$ ), and (3) the proportion of women reporting nonzero completed fertility in education group $j$ and year $t\left(p_{j t}\right)$. The first part of Eq. $1\left(\left[c f_{j t}-1\right]{ }^{*} s_{j t}\right)$, represents the average number of years women spend as mothers of young children before the birth of their last child. Six is added to this quantity because this is the number of years last children contribute to the total years women spend with children under age six. Thus, for 
example, if no women are childless $\left(p_{j t}=1\right)$, completed fertility among women with children equals three, and average child spacing is 1.5 years, women would spend 9 years on average as the biological mothers of children younger than six. If all women have one child, then $\left(\left[c f_{j t^{-}}\right.\right.$ $1]^{*} s_{j t}$ ) equals 0 and average years spent with children is 6 .

To incorporate childless women, Eq. 1 is scaled by the proportion of women who report non-zero completed fertility $\left(p_{j t}\right)$. The equation is a weighted average of the number of years childless women spend as mothers of young children (which is zero and therefore is not included in the equation) and the number of years women who do bear children spend as mothers of young children. Thus, Eq. 1 is the expected number of years that all women (not just those with children) can expect to spend as biological mothers of children under six. ${ }^{2}$

One drawback to this equation is that it does not incorporate infant and child mortality, although this information could be incorporated using life table information on mortality probabilities by education. However, because child and infant mortality is low in the United States, we do not expect this to substantially bias our results. Thus, our estimates assume child survival through age six.

To estimate the contribution of changes in birth spacing to trends in years spent as mothers of young children, we modify Eq. 1 by replacing year-specific birth spacing for each education group with birth spacing for the earliest period (1967-1969):

$$
\left(\left(\left[c f_{j t}-1\right] * s_{j 1967-1969}\right)+6\right) * p_{j t}
$$

The remainder of change in years spent as mothers of young children is due to changes in fertility (birth spacing, $c f_{j t}$, and the proportion of women with children, $p_{j t}$ ).

To estimate the contribution of increases in the prevalence of MPF (compositional shifts), first note that we can rewrite Eq. 1 by separating the portion of the equation for women who have births into a weighted average for women with MPF and without MPF. To estimate the contribution of the increasing prevalence of MPF to the years women spend as the biological mothers of young children, we hold the distribution of MPF constant at its 1967-1969 values:

$$
\left(\left[p m_{j 1967-1969} *\left(\left(\left[c f^{n}{ }_{j t}-1\right]^{*} s_{j t}^{m}\right)+6\right)\right]+\left[\left(1-p m_{j 1967-1969}\right) *\left(\left(\left[c f_{j t}^{n m}-1\right]^{*} s_{j t}^{n m}\right)+6\right)\right]\right) * p_{j t}
$$

where $p_{\text {j1967-1969 }}$ is the proportion of women with MPF in education category $j$ in year 19671969, superscript $m$ indicates quantities for those with MPF, superscript $n m$ indicates quantities for those without MPF, and all else is defined as above.

Finally, to quantify the relative impact of the increase in MPF prevalence (compositional effects) versus birth spacing, we additionally hold birth spacing constant within MPF groups as follows:

$$
\left(\left[p m_{j 1967-1969} *\left(\left(\left[c f^{m}{ }_{j t}-1\right] * s^{m}{ }_{j 1967-1969}\right)+6\right)\right]+\left[\left(1-p m_{j 1967-1969}\right) *\left(\left(\left[c f^{n m_{j t}}-1\right]{ }^{*} s^{n m}{ }_{j 1967-1969}\right)+6\right)\right]\right) * p_{j t}
$$

\footnotetext{
${ }^{2}$ Equation 1 holds at the individual-level, but we evaluate the function using average values of completed fertility and birth spacing. Given that the equation is non-linear, the average of the function is not necessarily equal to the function evaluated at the averages. Sensitivity tests show that trends and patterns estimated at the individual level are quite similar to those estimated using Eq. 1 evaluated at the averages although estimates at the individual level are somewhat lower (by about half a year). We estimate the function evaluated at the average because it allows for the decomposition of trends and differences into parts due to completed fertility and birth spacing.
} 
We estimate the independent contribution of trends in birth spacing within MPF groups by taking the difference between the counterfactuals implied by Eq. 4 and those implied by Eq. 3. Remaining trends are due to trends in fertility.

We supplement our analysis by examining child age spacing in the decennial census and American Community Survey (ACS) to test whether patterns of spacing including non-biological children are substantially different from those using birth spacing information. In this supplementary analysis, child age spacing is measured as the difference in coresidential child ages among women who are biological or social mothers of coresidential children.

In all analyses, estimates are weighted using person-level weights to correct for stratified sampling and non-response.

\section{$4 \quad$ Results}

\subsection{Completed Fertility, Birth Spacing, and Trends in Years Spent as Mothers of Young Children}

Figure 1 shows trends in women's completed fertility by education using data from the 2014 SIPP. Panel A shows trends for all women (including those whose completed fertility is zero). Consistent with past work (Isen and Stevenson 2011; Yang and Morgan 2003), more educated women have fewer children than less educated women, but the trends across education levels have been quite similar since at least the 1970s. The decline in completed fertility among women turning age 40 in the 1970s and 1980s represents the end of the baby boom, and like vital statistics data used to estimate birth rates (Smock and Schwartz 2020), trends using data from the SIPP show relative stability in completed fertility since then. Panel B shows trends in completed fertility for women who report non-zero completed fertility - the quantities used in Eq. 1. These trends are very similar to those for all women (Panel A). As shown in Fig. 2, this is because, although the proportion of women with non-zero completed fertility differs by education, trends in these proportions have been more or less parallel as well.

What about changes in birth spacing? Unlike completed fertility, Fig. 3 shows evidence of divergence in birth spacing. Since the 1970s, the average number of years between births has increased for all education groups, but more so for women with less education than for those with more. The dividing line appears to be a college degree, which is consistent with other research on differences in family patterns by education (Isen and Stevenson 2011; Lundberg, Pollak, and Stearns 2016; Martin 2006). The three education groups without a college degree have similar levels and trends and these are distinct from the slower rise in birth spacing for women with a college degree.

What are the implications of these trends for the number of years women can expect to be biological mothers of young children? Figure 4 plots trends estimated from Eq. 1. Because years spent as biological mothers of young children is both a function of completed fertility and birth spacing, there is more divergence by education in these trends than in completed fertility alone. Increases in birth spacing particularly impact the number of years spent as mothers among women with less than a high school degree. This is because wider birth spacing occurs over more total children, which increases the years spent with children to a larger extent than the same 
increase in average spacing would produce for groups with lower completed fertility. Thus, despite the fact that women with less than high school experienced a roughly parallel drop in completed fertility compared with other educational groups, their average number of years spent as biological mothers of young children increased between the late 1960s and 2010s.

As shown in Table 1, for women turning 40 in 2010-2017, we estimate that those with less than high school spent about 14 years as biological mothers of young children (row [B]). If we consider women's working ages to be between 18 and 64, then this means that this cohort of women were biological mothers of young children for about $30 \%$ of these years - a substantial percentage of their working lives. By contrast, women with college degrees turning 40 in 20102017 were biological mothers of young children for only 8.2 years or $18 \%$ of their working lives. In addition, Table 1 shows the extent to which these inequalities have grown. In the late 1960s, college graduate women spent an average of about four fewer years as mothers of young children compared to women without high school degrees (13.01-8.97) whereas they spent almost six fewer years in the 2010s (13.88-8.15).

If patterns of birth spacing by education had not changed since 1967-1969, what would trends in years spent as mothers of young children have been? We estimate these counterfactual trends using Eq. 2, which holds birth spacing for each education group constant at the earliest period (1967-1969). Table 1 shows that if education-specific spacing patterns had not changed, each education group would have spent fewer years as biological mothers of young children (row $[C])$. However, the impact is greatest for women with the least education for whom we estimate that birth spacing added almost two years $(1.73$, row $[\mathrm{E}])$ to the time that women without high school degrees spent as mothers of young children. Estimates for the other education groups are smaller, ranging from about half a year to one year. Thus, these results support the hypothesis that less educated women's years spent as mothers of young children have been particularly affected by changes in birth spacing.

While changes in birth spacing increased the number of years women spent as biological mothers of young children, declines in fertility reduced years spent. We estimate the independent contribution of trends in fertility by taking the difference between the counterfactual holding birth spacing constant and a counterfactual scenario in which both birth spacing and fertility remained constant (row $[\mathrm{C}]-[\mathrm{D}]$ as shown in row $[\mathrm{F}]$ ). Row $[\mathrm{F}]$ shows that declining fertility reduced women's years spent as mothers of young children over this period at the low end by 0.86 years for women with less than a high school degree and at the high end by 3.19 years for women with some college. Thus, increases in birth spacing offset declines in years spent as mothers implied by declining fertility for women in all four education groups. Nevertheless, the extent to which birth spacing offset these declines varies. Row $[\mathrm{H}]$ of Table 1 shows that the impact of changes in birth spacing was particularly dramatic for women without a high school degree. If birth spacing patterns had been constant at their 1967-1969 levels, years spent as mothers of young children for this group would have declined along with falling completed fertility to 12.15 years, but instead, increases in birth spacing reversed this trend resulting in an observed increase in years spent with young children to 13.88 years (offsetting declines by $201 \%$ ). Increases in birth spacing substantially offset declines in years spent with young children for other educational groups as well but to a lesser extent, offsetting declines implied by reduced fertility by between $32-41 \%$ (row $[\mathrm{H}]$ ).

Trends in birth spacing also contributed to growing inequality by education in years spent with young children. If patterns of birth spacing by education had not changed, educational differences in years spent as biological mothers would have been smaller than observed in 2010- 
2017. For example, women with less than a high school degree would have spent 4.56 more years with children under six than women with college degrees (12.15-7.58) versus the observed 5.73 years $(13.88-8.15)$.

\subsection{MPF and Trends in Years Spent as Mothers of Young Children}

What role have trends in MPF played in trends in years spent as mothers of young children for women with different education levels? Figure 5 shows that MPF has increased to a greater extent for women with less than a college degree and, like our other results, a college degree appears to be the major dividing line in these patterns. Although women with less than a high school degree were the most likely to have had MPF in 2010-2017 (29\%), women with high school degrees and some college were not far behind. By contrast $11 \%$ of college graduate women turning 40 in 2010-2017 had had MPF. Past research on MPF has primarily examined cross-sectional patterns or trends between two cohorts (Amorim and Tach 2019; Carlson and Furstenberg 2006; Stykes and Guzzo 2019; Thomson et al. 2014). Our results show that, like many other family behaviors, there is growing educational divergence in MPF.

If MPF is associated with higher completed fertility and wider birth intervals, then the rise of MPF may account for educational differences in the number of years women are the biological mothers of young children. Indeed, results from a linear regression in which completed fertility among women with children is the dependent variable, the independent variables are dummy variable indicators for education $(<12,12,13-15,16+)$, dummy variables for the decade women turned 40, and a dummy variable for whether or not women had MPF, and $B$ is the MPF coefficient to be estimated, reveals that women with MPF have had almost one additional child compared with women without $\operatorname{MPF}(\beta=0.97 ; \mathrm{p}<.01)$. A similar regression with birth spacing as the dependent variable indicates that women with MPF also have wider birth intervals than those without MPF by about 1.6 years on average $(\beta=1.56 ; p<.01)$.

If the prevalence of MPF had not increased since 1967-1969, what would trends in years spent as mothers of young children have been? This counterfactual is estimated using Eq. 3 and presented in row [C] of Table 2. Indeed, the increasing prevalence of MPF is associated with increases in the number of years women spent as biological mothers of young children. For example, if MPF had not increased among women with less than a high school degree but all else had changed as observed, then the number of years spent as mothers of young children would have increased only slightly (from 13.01 to 13.13 years) rather than by almost one year as observed (from 13.01 to 13.88). Row [E] shows that, in terms of magnitude, increases in MPF had the largest impact on women who had completed some college, increasing their years spent as mothers of young children by 1.23 on average.

Thus, both increases in the prevalence of MPF and birth spacing have offset declines in the number of years women spent as mothers of young children associated with declining completed fertility. To estimate the relative impact of the increase in MPF prevalence (compositional effects) versus birth spacing, we hold birth spacing within MPF groups and MPF prevalence levels constant at their 1967-1969 levels using Eq. 4. Row [E] of Table 2 shows that this counterfactual reduces the time spent as mothers of young children even further for all educational groups relative to observed 2010-2017 values. This reflects the fact that birth spacing trends diverged by education even within categories of MPF. In particular, educational 
differences in birth spacing diverged for women without MPF (see Appendix Table 1 for trends within MPF groups).

We estimate the independent contribution of trends in birth spacing within MPF groups by taking the difference between the two counterfactuals (row [C]-[D] as shown in row [F]). Rows $[\mathrm{H}]$ and $[\mathrm{I}]$ show that the contribution of MPF and birth spacing differ by educational group with the larger contributions of birth spacing within MPF groups for women with less than a high school degree and larger contributions of the increasing prevalence of MPF for women with more education. Given evidence suggesting that the direct measure of MPF used in the SIPP may underestimate the prevalence of MPF especially for more disadvantaged women (Stykes and Guzzo 2019), it is possible that the larger contribution of birth spacing changes for less educated women is due to MPF underreporting. With this caveat in mind, however, rows [J]-[L] in Table 2 show that both increases in MPF and birth spacing within MPF groups contributed to growing educational differences in the number of years women spent as biological mothers of young children.

\subsection{Sensitivity tests}

To test whether the inclusion of all children (not just biological children) may affect our results, we turn to an analysis using the 1960-2000 U.S. decennial censuses and the 2001-2017 American Community Survey (Ruggles et al. 2010). Although it is not possible with these data to estimate the number of years women spent as mothers of young biological and non-biological children given that they are not longitudinal, we can examine patterns of child age spacing among all children in households to determine if they substantially differ from estimates of birth spacing from the SIPP.

Figure 6 shows trends in coresidential children's age spacing by women's education among women living with two or more children. These trends are very similar to those for birth spacing from the SIPP shown in Fig. 3. The child age spacing estimates are lower from the census and ACS (Fig. 6) than the birth spacing estimates (Fig. 3), but this is to be expected given that children with wide age gaps are less likely to be captured coresiding in households in crosssectional data. Given the different data structures, however, it is remarkable how similar trends in child age spacing from the census and ACS are to birth spacing from the SIPP. Trends in spacing have diverged and college graduates appear to be different from women with less education, who have similar trends and levels of spacing. It is also worth noting that there are hints of a recent increase in spacing using the SIPP data among women with less than a high school degree and this is more evident in the ACS. Thus, we expect that the results of our SIPP analysis would be robust to the inclusion of non-biological children.

\section{Discussion}

Despite remarkably parallel declines in completed fertility by education, our analysis has shown that growing educational differences in birth spacing produced educational divergence in the number of years women spend as mothers of young children. In the late 1960s, college graduate women spent an average of about four fewer years of their lives as mothers of young children 
compared to women without high school degrees whereas they spent almost six fewer years in the 2010s.

Declining fertility across all education groups has led to declines in the number of years women spent as mothers of young children by between about one and three years. But increases in birth spacing offset these declines. Particularly striking is the finding that increases in birth spacing reversed declines in years spent as mothers for women with less than a high school degree such that they spent more years with young children in the 2010s than in the late 1960s. Increases in birth spacing offset declines in years spent as mothers of young children for women with more education as well, but to a lesser extent. These findings are significant because young children have been found to be particularly important for mothers' labor force attachment, leisure time, and time spent on care work activities like basic childcare (Cotter et al. 2007; Meier et al. 2018).

Our findings are surprising on the one hand given that education differences in completed fertility have been very consistent since the late 1960s across the education groups we examine. On the other hand, our results are unsurprising given that they are consistent with divergence by education in other measures of fertility including age at first birth, non-marital fertility, and MPF. Thus, our research reveals yet another way in which patterns of family life have diverged by education in the United States - growing educational differences in birth spacing that have translated into growing inequality in the number of years women spend as the biological mothers of young children.

We also investigated the role of MPF in this educational divergence. Women with children from multiple partners tend to have higher completed fertility and wider birth intervals. Indeed, we found that the increasing prevalence of MPF is associated with growing educational differences in years spent as mothers of young children. We estimate that the growing prevalence of MPF added between 0.75 and 1.23 years to the average time women without a college degree spent as mothers of young children between the late 1960s and 2010s. But even mothers without MPF experienced growing educational differences in birth spacing and thus MPF is not the sole explanation for increases in birth spacing and by extension growing differences in years spent with young children.

The descriptive trends shown here can be elaborated upon in several ways in future research. For instance, we estimate the total number of years women spent in the status of biological mothers of young children rather than time spent with young children by hours of care or other measures of intensity. Past research suggests that more educated mothers spend more time with their children, engaging in concerted cultivation and intensive mothering (Hays 1998; Lareau 2003). These tendencies have become more pronounced, so as more educated women have experienced declines in years spent as mothers to young children, both overall and relative to less educated mothers, increases in the intensity of time spent caring for children may have offset these declines.

A related point is that having multiple children under the age of six may have stronger effects on women's labor market outcomes than having just one. Thus, one hypothesis is that wider birth spacing may be beneficial to women's labor market outcomes if it minimizes the time that women have multiple young children in the household or if wider birth spacing allows women to return to work between births (Gough 2017; Troske and Voicu 2013). Consistent with this is the finding that women with short birth intervals (less than two years) tend to have lower cumulative work hours and earnings later in life than those with longer birth intervals (Gough 2017). But the association is non-linear - women with longer birth intervals (7-8 years apart) 
also tend to have lower cumulative work hours and earnings than those with birth intervals in the 2 to 6 year range. However, it is difficult to extrapolate these findings to the long-term effects of the interaction between numbers and spacing of children. This is an area for additional research.

Trends in the timing of births may also affect the implications of these patterns. College educated women tend to have children later than less educated women and this delay has become more pronounced (Isen and Stevenson 2011; McLanahan 2004). Past work has indicated that fertility delay is associated with higher wages for college educated mothers, but it is not tied to the same benefits for mothers with less education (Amuedo-Dorantes and Kimmel 2005; Doren 2019). This is likely related to how age and career trajectories align for mothers with different levels of education. Thus, future research could explore connections between changes in the timing of births and years spent as mothers of young children to investigate whether they have differential relationships with work-related outcomes, including labor force participation, earnings, and wages.

Future work could also build on our findings by applying an intersectional framework, considering how race and nativity interact with education to shape women's years as mothers of young children. Minority and immigrant women tend to have higher fertility than white and U.S.-born women (U.S. Census Bureau 2019b: Table 6), which suggests that the patterns we observe may not fully describe the experiences of all women. In addition, understanding the role of single motherhood and how many of these years are spent as single mothers of young children as opposed to partnered mothers could also further our understanding of inequalities of experience across mothers. 
Table 1 Observed and Counterfactual Trends in Years Spent as Mothers of Young Children, Holding Birth Spacing \& Fertility at 1967-69 Levels

\author{
Education level
}

Less than high school High school Some college College or more

Observed

[A] 1967-69

13.01

12.47

12.39

8.97

[B] 2010-17

13.88

10.78

10.23

8.15

[C] Holding birth spacing constant, 2010-

2017

9.96

9.20

7.58

[D] Holding birth spacing constant +

fertility constant, 2010-17

13.01

12.47

12.39

8.97

[E] Part due to birth spacing trends $=[B]-[C]$

1.73

0.82

1.03

0.56

$[\mathrm{F}]$ Part due to fertility trends $=[\mathrm{C}]-[\mathrm{D}]$

$-0.86$

$-2.51$

$-3.19$

$-1.39$

[G] Total

0.87

$-1.69$

$-2.16$

$-0.82$

$[\mathrm{H}] \%$ change offset by birth spacing trends

$=[\mathrm{E}] /([\mathrm{A}]-[\mathrm{C}])$

200.7

32.6

32.4

40.5

Source: 2014 Survey of Income and Program Participation, Waves 1-4 
Table 2 Observed and Counterfactual Trends in Years Spent as Mothers of Young Children, Holding MPF Prevalence \& Birth Spacing within MPF Groups at 1967-69 Levels

Education level

Less than high school High school Some college College or more

Observed

[A] 1967-69

13.01

12.47

12.39

8.97

[B] 2010-17

13.88

10.78

10.23

8.15

[C] Holding MPF constant, 2010-2017

9.76

9.00

[D] Holding MPF constant + birth spacing constant within MPF groups, 2010-17

11.57

9.34

8.54

7.45

[E] Part due to MPF compositional change $=[\mathrm{B}]-[\mathrm{C}]$

0.75

1.02

[F] Part due to birth spacing within $\mathrm{MPF}=[\mathrm{C}]-[\mathrm{D}]$

0.42

0.46

0.28

[G] Total

1.44

1.69

0.70

$[\mathrm{H}] \%$ due to changes in MPF

32.6

70.8

72.6

59.2

[] $\%$ due to changes in birth spacing within MPF groups

29.2

27.4

40.8

[] Observed education difference vs. college or more 2010-17

$[\mathrm{K}]$ Counterfactual education difference, holiding MPF constant, 2010-17

[L] Counterfactual education difference, holiding MPF and birth spacing constant, 2010-17

1.1 


\section{Fig. 1 Trends in Completed Fertility by Education}

Panel A. All Women

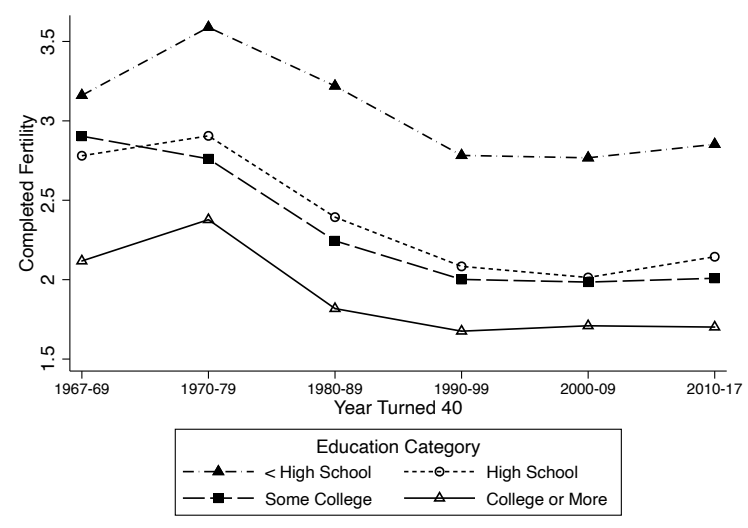

Panel B. Women with Children

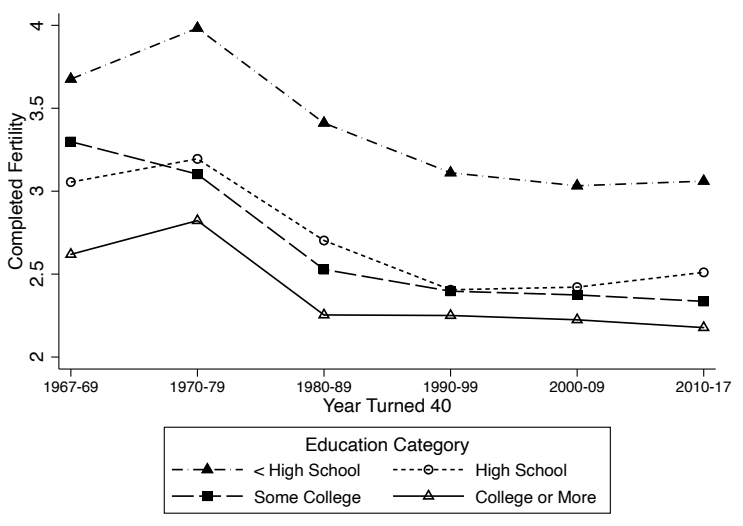

Source: 2014 Survey of Income and Program Participation, Waves 1-4 
Fig. 2 Trends in the Proportion of Women with Non-Zero Completed Fertility by Education

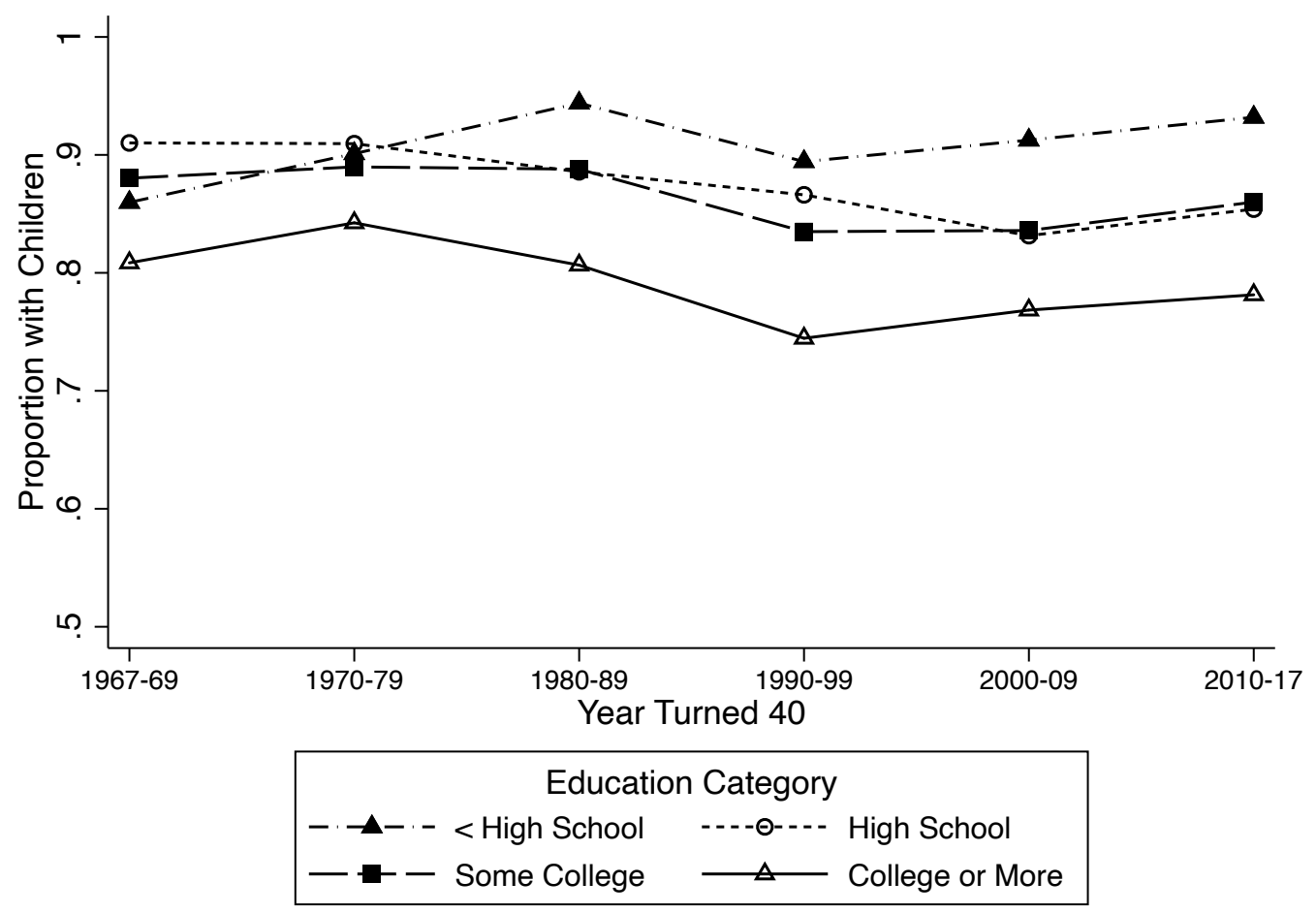

Source: 2014 Survey of Income and Program Participation, Waves 1-4 
Fig. 3 Trends in Birth Spacing by Education (Women with 2 or More Children)

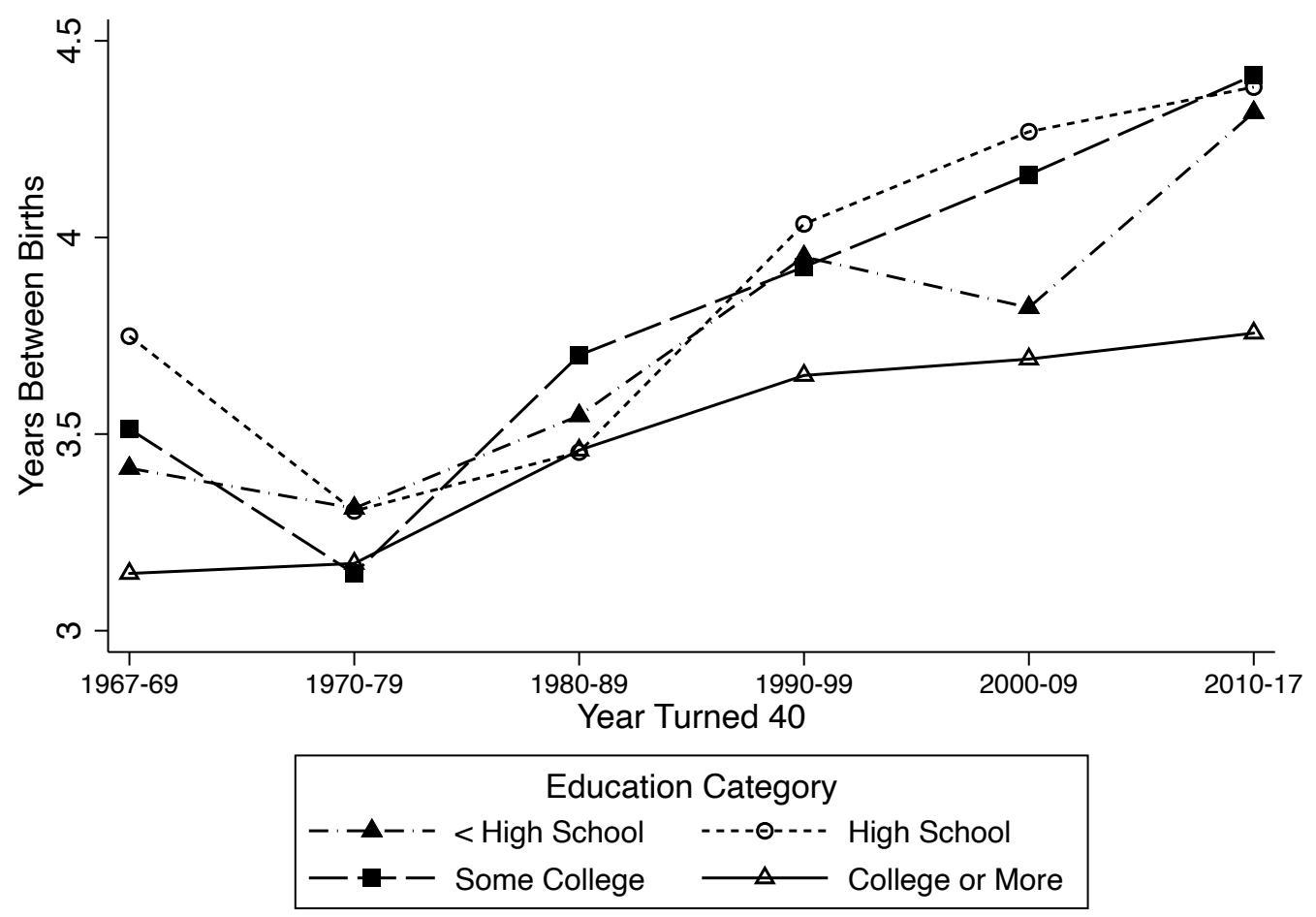

Source: 2014 Survey of Income and Program Participation, Waves 1-4 
Fig. 4 Trends in Estimated Years Spent as Mothers of Young Children by Education

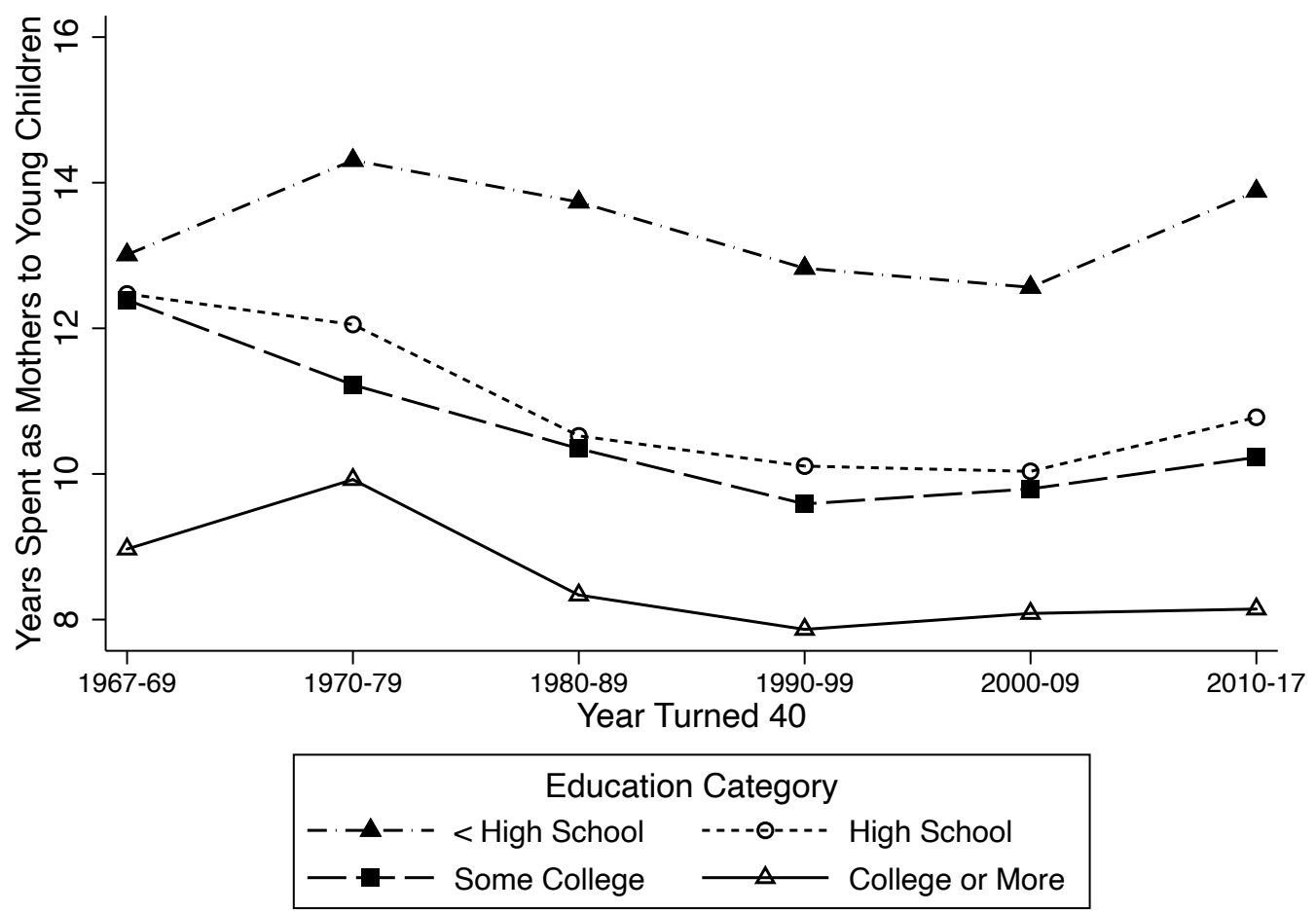

Source: 2014 Survey of Income and Program Participation, Waves 1-4 
Fig. 5 Trends in Multiple Partner Fertility by Education (Women with Children)

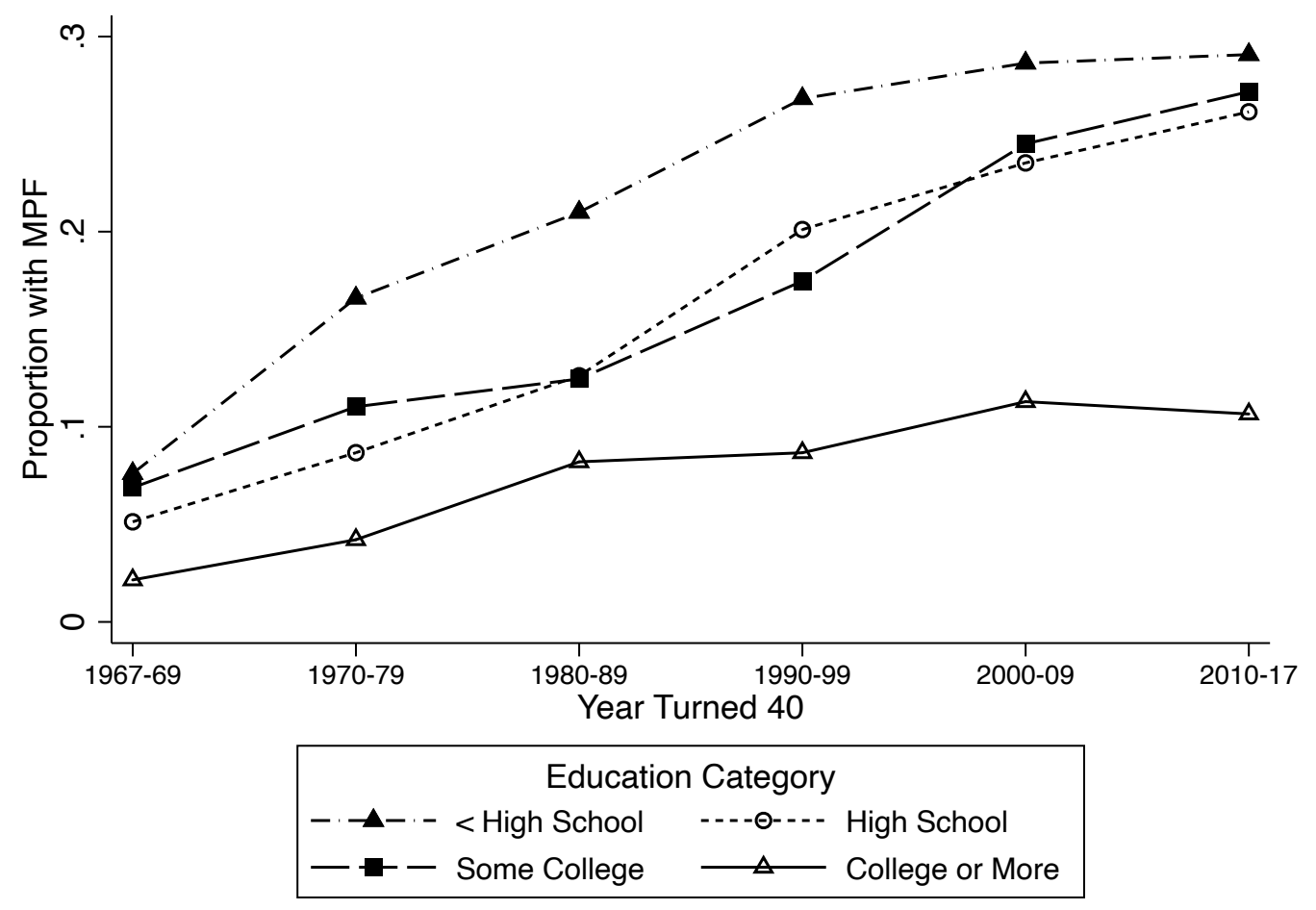

Source: 2014 Survey of Income and Program Participation, Waves 1-4 
Fig. 6 Trends in Coresidential Children's Age Spacing by Education (Women Living with 2 or More Children)

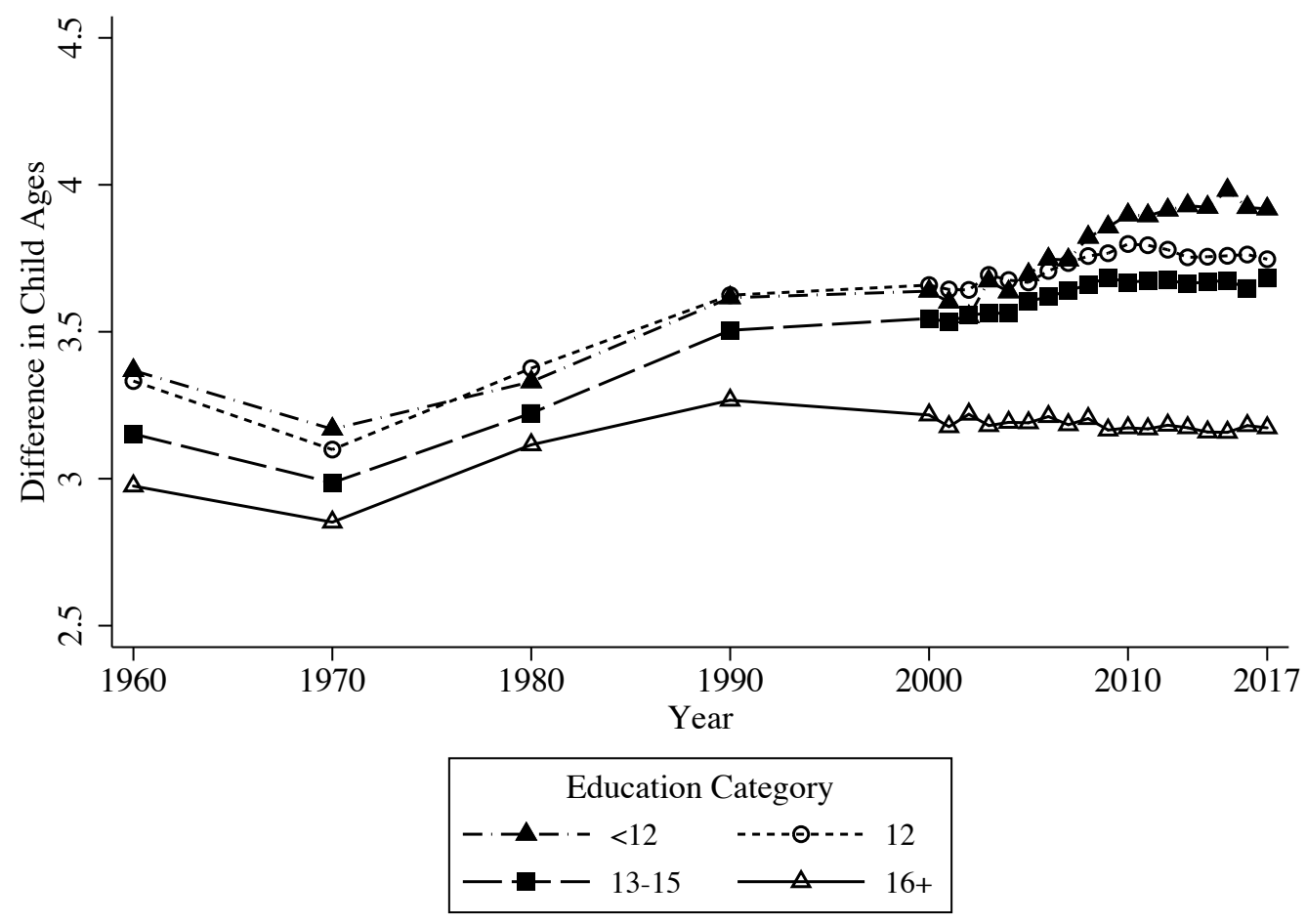

Source: 1960-2000 U.S. decennial census and 2001-2017 American Community Survey data 
Appendix Table 1 Selected Trends and Distributions

1967-1969 2010-2017

\begin{tabular}{|c|c|c|}
\hline \multicolumn{3}{|l|}{ Percentage distribution (\%) } \\
\hline Less than high school & 25.59 & 9.75 \\
\hline High school & 41.40 & 22.24 \\
\hline Some college & 18.23 & 27.78 \\
\hline College or more & 14.79 & 40.22 \\
\hline \multicolumn{3}{|l|}{ Completed fertility } \\
\hline \multicolumn{3}{|l|}{ Women with MPF } \\
\hline Less than high school & 5.26 & 3.66 \\
\hline High school & 4.04 & 3.19 \\
\hline Some college & 4.30 & 3.12 \\
\hline College or more & 3.00 & 2.88 \\
\hline \multicolumn{3}{|l|}{ Women without MPF } \\
\hline Less than high school & 3.55 & 2.82 \\
\hline High school & 3.00 & 2.27 \\
\hline Some college & 3.22 & 2.04 \\
\hline College or more & 2.61 & 2.09 \\
\hline \multicolumn{3}{|c|}{ Birth spacing (years between births) } \\
\hline \multicolumn{3}{|l|}{ Women with MPF } \\
\hline Less than high school & 3.21 & 4.38 \\
\hline High school & 3.84 & 5.12 \\
\hline Some college & 3.45 & 5.63 \\
\hline College or more & 6.21 & 5.87 \\
\hline \multicolumn{3}{|l|}{ Women without MPF } \\
\hline Less than high school & 3.43 & 4.29 \\
\hline High school & 3.74 & 4.03 \\
\hline Some college & 3.52 & 3.75 \\
\hline College or more & 3.07 & 3.42 \\
\hline
\end{tabular}

Source: 2014 Survey of Income and Program Participation, Waves 1-4 


\section{References}

Amorim, M., \& Tach, L. M. (2019). Multiple-partner fertility and cohort change in the prevalence of half-siblings. Demography, 1-29.

Amuedo-Dorantes, C., \& Kimmel, J. (2005). The motherhood wage gap for women in the United States: The importance of college and fertility delay. Review of Economics of the Household, 3(1), 17-48.

Autor, D. H. (2014). Skills, education, and the rise of earnings inequality among the "other 99 percent". Science, 344(6186), 843-851.

Avellar, S., \& Smock, P. J. (2003). Has the price of motherhood declined over time? A crosscohort comparison of the motherhood wage penalty. Journal of Marriage and Family, 65(3), 597-607.

Carlson, M. J., \& Furstenberg, F. F. (2006). The prevalence and correlates of multipartnered fertility among urban US parents. Journal of Marriage and Family, 68(3), 718-732.

Cotter, D., England, P., \& Hermsen, J. (2007). Moms and jobs: Trends in mothers' employment and which mothers stay home. A fact sheet from Council on Contemporary Families.

Doren, C. (2019). Which mothers pay a higher price? Education differences in motherhood wage penalties by parity and fertility timing. Sociological Science, 6, 684-709.

Fomby, P., \& Bosick, S. J. (2013). Family instability and the transition to adulthood. Journal of Marriage and Family, 75(5), 1266-1287.

Gough, M. (2017). Birth spacing, human capital, and the motherhood penalty at midlife in the United States. Demographic Research, 37, 363-416.

Guzzo, K. B. (2014). New partners, more kids multiple-partner fertility in the United States. The ANNALS of the American Academy of Political and Social Science, 654(1), 66-86.

Härkönen, J. (2017). Diverging destinies in international perspective: Education, single motherhood, and child poverty. Retrieved from https://www.econstor.eu/bitstream/10419/169273/1/713.pdf

Hays, S. (1998). The cultural contradictions of motherhood: Yale University Press.

Hazan, M., \& Zoabi, H. (2015). Do highly educated women choose smaller families? The Economic Journal, 125(587), 1191-1226.

Holland, J. A., \& Thomson, E. (2011). Stepfamily childbearing in sweden: Quantum and tempo effects, 1950-99. Population Studies, 65(1), 115-128.

Isen, A., \& Stevenson, B. (2011). Women's education and family behavior: trends in marriage, divorce, and fertility. In J. B. Shoven (Ed.), Demography and the Economy (pp. 107142). Chicago: University of Chicago Press.

Kalil, A., Ryan, R., \& Corey, M. (2012). Diverging destinies: Maternal education and the developmental gradient in time with children. Demography, 49(4), 1361-1383.

Kalmijn, M. (2013). The educational gradient in marriage: A comparison of 25 European countries. Demography, 50(4), 1499-1520. doi:Doi 10.1007/S13524-013-0229-X

King, R. B. (1999). Time spent in parenthood status among adults in the United States. Demography, 36(3), 377-385.

Lareau, A. (2003). Unequal childhoods: Class, race, and family life. Berkeley: University of California Press.

Li, J.-C. A. (2006). The institutionalization and pace of fertility in American stepfamilies. Demographic Research, 14, 237-266. 
Livingston, G., Parker, K., \& Rohal, M. (2015). Childlessness falls, family size grows among highly educated women. Washington, DC: Pew Research Center. .

Lundberg, S., Pollak, R. A., \& Stearns, J. (2016). Family inequality: Diverging patterns in marriage, cohabitation, and childbearing. Journal of Economic Perspectives, 30(2), 79102.

Martin, S. P. (2006). Trends in marital dissolution by women's education in the United States. Demographic Research, 15, 537-560.

Matthews, T. J., \& Hamilton, B. E. (2009). Delayed childbearing: More women are having their first child later in life. Retrieved from https://www.cdc.gov/nchs/data/databriefs/db21.pdf

McLanahan, S. (2004). Diverging destinies: How children are faring under the second demographic transition. Demography, 41(4), 607-627.

Meier, A., Musick, K., Fischer, J., \& Flood, S. (2018). Mothers' and fathers' well-being in parenting across the arch of child development. Journal of Marriage and Family, 80(4), 992-1004.

Pal, I., \& Waldfogel, J. (2016). The family gap in pay: New evidence for 1967 to 2013. RSF: The Russell Sage Foundation Journal of the Social Sciences, 2(4), 104-127.

Raymo, J. M., Carlson, M. J., VanOrman, A., Lim, S.-j., Perelli-Harris, B., \& Iwasawa, M. (2015). Educational differences in early childbearing: A cross-national comparative study. Demographic Research, 33, 65.

Ruggles, S., Flood, S., Goeken, R., Grover, J., Meyer, E., Pacas, J., \& Sobek, M. (2018). Integrated public use microdata series: Version 8.0. [Machine-readable database]. Minneapolis, MN: University of Minnesota.

Shang, Q., \& Weinberg, B. A. (2013). Opting for families: Recent trends in the fertility of highly educated women. Journal of Population Economics, 26(1), 5-32.

Smock, P. J., \& Schwartz, C. R. (2020). The demography of families: A review of patterns and change. Journal of Marriage and Family, 81, 9-34.

Stykes, J. B., \& Guzzo, K. B. (2019). Multiple-partner fertility: variation across measurement approaches. In Analytical Family Demography (pp. 215-239): Springer.

Thomson, E., Lappegård, T., Carlson, M. J., Evans, A., \& Gray, E. (2014). Childbearing across partnerships in Australia, the United States, Norway, and Sweden. Demography, 51(2), 485-508.

Thomson, E., Winkler-Dworak, M., Spielauer, M., \& Prskawetz, A. (2012). Union instability as an engine of fertility? A microsimulation model for France. Demography, 49(1), 175195.

Troske, K. R., \& Voicu, A. (2013). The effect of the timing and spacing of births on the level of labor market involvement of married women. Empirical Economics, 45(1), 483-521.

U.S. Census Bureau. (2019a). Table A-1. Years of school completed by people 25 years and over, by age and sex: Selected years 1940 to 2018. Suitland, MD: U.S. Census Bureau.

Retrieved from https://www.census.gov/data/tables/time-series/demo/educationalattainment/cps-historical-time-series.html.

U.S. Census Bureau. (2019b). Fertility of women in the United States: 2018. Suitland, MD: U.S. Census Bureau. Retrieved from https://www.census.gov/data/tables/2018/demo/fertility/women-fertility.html\#par_list_62

Wineberg, H., \& McCarthy, J. (1989). Child spacing in the United States: recent trends and differentials. Journal of Marriage and the Family, 213-228. 
Yang, Y., \& Morgan, S. P. (2003). How big are educational and racial fertility differentials in the US? Social Biology, 50(3-4), 167-187. 